Document downloaded from:

http://hdl.handle.net/10251/77536

This paper must be cited as:

Llorca Garcia, C.; Ángel -Domènech, A.; Agustin Gomez, F.; García García, A. (2017). Motor vehicles overtaking cyclists on two-lane rural roads: Analysis on speed and lateral clearance. Safety Science. 92:302-310. doi:10.1016/j.ssci.2015.11.005.

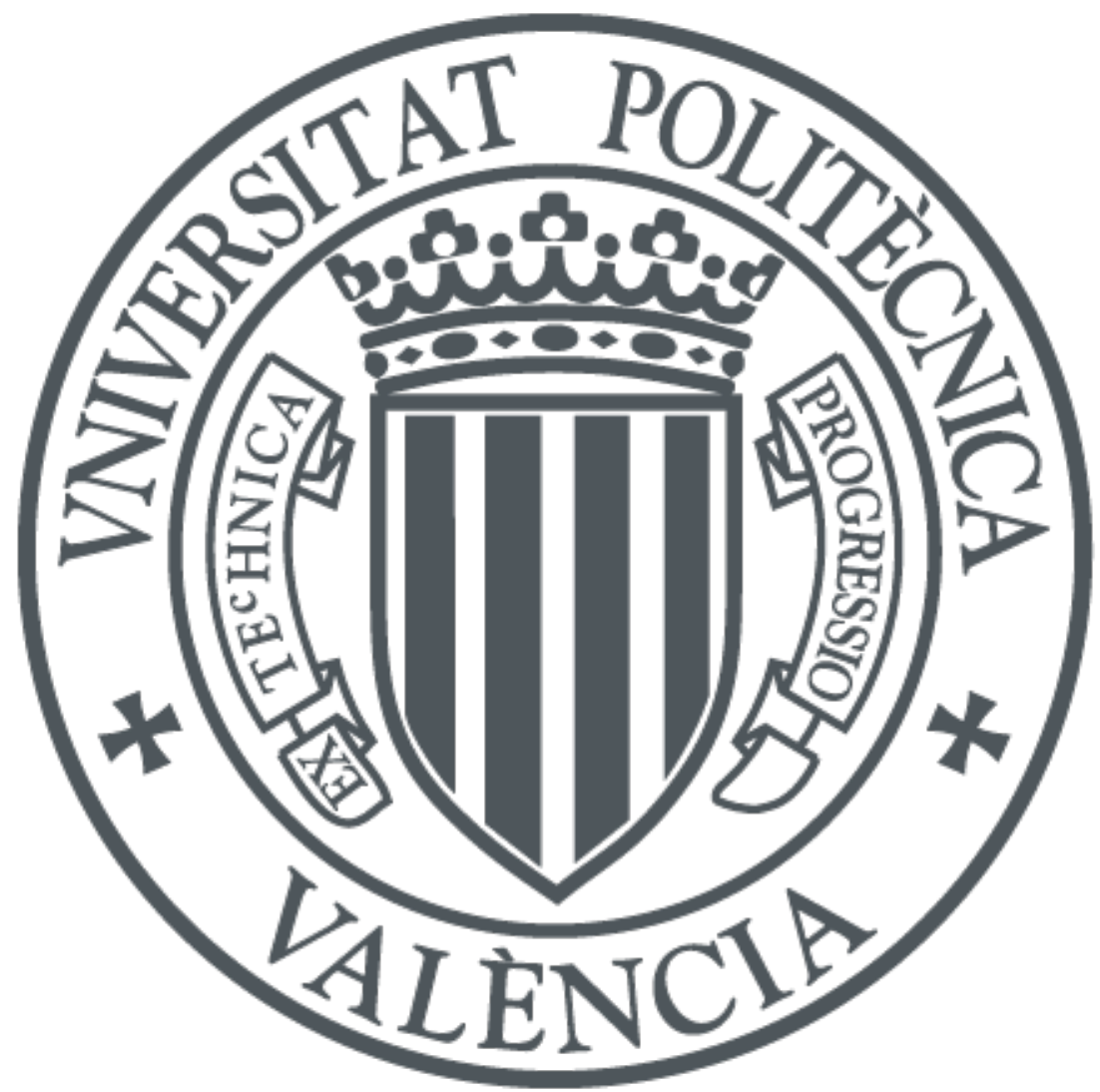

The final publication is available at

http://dx.doi.org/10.1016/j.ssci.2015.11.005

Copyright Elsevier

Additional Information 


\section{Motor vehicles overtaking cyclists on two-lane rural roads: analysis on speed and lateral clearance}

ABSTRACT

Two-lane rural roads in Spain accommodate significant bicycle traffic volumes, mainly associated to sport and leisure activities. Motor vehicles' higher speed, weight and volume, compared to cyclists, represent a serious safety concern when overtaking a bicycle. Spanish traffic rules determine a minimum $1.5 \mathrm{~m}$ lateral distance.

This research characterized 2,928 overtaking manoeuvres in the overtaking lateral clearance between motor vehicle and bicycle, as well as in the motor vehicle speed, in contrast with previous research. Two instrumented bicycles were equipped with laser rangefinders, a GPS tracker and three video cameras. They rode along seven rural road segments at a speed between 15 and $25 \mathrm{~km} / \mathrm{h}$, centred on the paved shoulder, or as close as possible to the outer edge. Besides, this methodology allowed the characterization of the overtaken vehicle type, its left lane occupation as well as its interaction with opposing traffic flow. For each session, rider's general risk perception was also registered.

The analysis suggested that lateral clearance is not the only factor that influenced rider's risk perception, although current standards are only related to it. On the contrary, a combined factor of lateral clearance, vehicle type and vehicle speed had a more significant correlation with the perceived risk. This agreed with literature models of transient aerodynamic forces between overtaking and overtaken vehicles. Results showed that effect of heavy vehicles on bicyclists was also strong. In addition to this, the combined factor of clearance and speed was higher on tangent sections where overtaking was permitted.

\section{KEYWORDS}

Bicycle, overtaking, sport cycling, two-lane rural road, lateral clearance, instrumented bicycle, risk perception. 
Two-lane rural roads in Spain accommodate significant bicycle traffic volumes, mainly associated to sport and leisure activities. According to Spanish traffic regulations (Ministerio del Interior, 2003), cyclists must ride as close as possible to the outer edge of the road, on the shoulder if it exists. This research focuses on two-lane rural roads, which do not have any specific lane marking for bicycles. Motor vehicles that overtake cyclists must keep a minimum lateral distance of $1.5 \mathrm{~m}$.

According to Spanish Traffic Directorate (2013), there were 5,835 accidents with personal injuries or deaths involving bicycles in Spain in 2013. Only $26 \%$ of accidents occurred in rural roads, being the rest on urban areas. However, $46 \%$ of severe injuries ( 297 of 646 severe injuries) corresponded to rural roads. Moreover, the proportion of deaths in rural roads with respect of the total was up to $65 \%$ (45 of 69 deaths). Despite the higher use of bicycles on urban environments, cycling on rural roads represents a serious safety concern, affecting around 45 deaths a year in 2013. Compared to urban areas, the severity of crashes involving bicycles on rural roads is much higher.

Previous research reported this higher severity. Boufous et al. (2012) found that, although only a $5 \%$ of bicycle crashes in Victoria region (Australia), their severity was higher (46\% of crashes involved severe injuries, compared to $33 \%$ on urban crashes). Those authors explained that the cause of this result was the higher speed of motor vehicles. Tin Tin et al., (2013) reported lower risk on rural roads compared to urban streets, although they did not analyse the severity.

Despite the higher relative severity of bicycle crashes on rural roads, there have been very few studies, compared to urban cycling safety. Results of urban safety analyses (Hamann and PeekAsa, 2013; Klassen et al., 2014; Osberg et al., 1998) cannot be extrapolated to overtaking manoeuvres of motor vehicles and bicycles on rural roads, because of the higher speeds of motor vehicles and the type of manoeuvres that take place on them.

For this reason, some researchers focused specifically on the observation of overtaking manoeuvres on rural road segments. Savolainen et al. (2012) installed video cameras on high masts to observe the interaction between motor vehicles and bicycles on a rural road tangent section in United States. They analysed how frequent motor vehicles crossed the centreline, as a function of the position of the cyclist on the road shoulders, the presence of opposing traffic or the existence of centreline rumble strips. However, they did not measure accurately the lateral separation between the bicycle and the motor vehicle at the overtaking time. Later, Kay et al. (2014) found that the average vehicular speeds were slightly reduced by the presence of a "Share the Road" sign treatment.

Alternatively, a research project in UK (Walker, 2007; Walker et al., 2014) developed an instrumented bicycle to observe motor vehicles overtaking it. This bicycle was equipped with an ultrasonic distance measurement sensor and a video camera. These authors investigated the influence of using a helmet as well as the effect of cyclist gender, cyclist clothing and bicycle position on the mean overtaking proximity (lateral distance between the motor vehicle and the bicycle). A sample of 2,355 manoeuvres were characterized. The absence of a helmet was related with slightly higher overtaking proximities, although a higher effect was associated with the bicycle distance from road edge. The larger the distance from the outer edge of pavement of the road, the smaller the mean overtaking proximity (from $1.40 \mathrm{~m}$ if the bicycle was only 0.25 $\mathrm{m}$ from the outer edge to $1.2 \mathrm{~m}$ if it rode $1.25 \mathrm{~m}$ from it). The influence of clothing visibility was small, and therefore authors could not provide any recommendation to prevent very close overtaking manoeuvres. Lastly, female-looking cyclists were associated with a higher lateral clearance. 
Chapman and Noyce (2012) used also an instrumented bicycle to observe overtaking manoeuvres on two-lane rural roads. This bicycle was equipped with two cameras and an ultrasonic sensor to measure the distance to the overtaking vehicles. Observing 1,151 manoeuvres the authors investigated the effect of motor vehicle type and existence of shoulder in centreline violations. Those violations were more frequent on highways without paved shoulders, which might be related with the necessity of keeping the same lateral distance, but on a narrower road. The violations of the 3 feet $(1 \mathrm{~m})$ lateral distance between motor vehicle and bicycle (named lateral clearance) were very rare. The study did not analyse the frequency distribution of the lateral clearance.

Love et al. (2012) studied the compliance of the three-foot $(1 \mathrm{~m})$ lateral separation regulation in Baltimore, Maryland. They also used an instrumented bicycle equipped with video-cameras, and measured only the lateral distance from video images. They evaluated the proportion of motor vehicles that kept that distance, although all the experiment took place on urban streets.

The above-cited studies only considered the overtaking proximity or distance between motor vehicle and bicycle. However, a previous study of this paper authors (García et al., 2015) used a highly instrumented bicycle to measure the speed of motor vehicles and the lateral distance during overtaking. The study was carried out in 7 road segments with different lane and shoulder widths. The main findings were that the lateral distance (and obviously the compliance of the $1.5 \mathrm{~m}$ criterion) decreased on narrow roads.

Although most of previous research did not measure or analysed the speed of motor vehicles in relation with the lateral distance, Ata and Langlois (2011) identified the collision risk as the combination of two factors: common space occupancy and aerodynamic effect of trucks or buses overtaking a cyclist. The effect of aerodynamic forces depended on both the lateral distance and the speed of the motor vehicle. These results showed that different combinations of speed and clearance generated the same aerodynamic forces. According to Ata and Langlois (2011), the aerodynamic force increased with speed and decreased with lateral distance. It is zero for distances over approximately $3 \mathrm{~m}$. Noger et al. (2005) presented a similar result, calculating the lateral force according to the equation 1.

$$
F_{y}=\frac{1}{2} \rho S V^{2} C_{y}
$$

\section{Where:}

- Fy: lateral force.

- $\rho$ : air density.

- $V$ : speed of the overtaking vehicle.

- $S$ : frontal area of the overtaking vehicle.

- $C y$ : dimensionless coefficient, which decrease with lateral distance.

Other studies (Corin et al., 2008; Noger et al., 2005; Uystepruyst and Krajnović, 2013) investigated aerodynamic forces between overtaking and overtaken vehicles. Their results also stated that aerodynamic forces are proportional to the square of the overtaking vehicle speed and decrease with lateral clearance. They only focused on overtaking between motor vehicles, and therefore, the results cannot be easily applied to bicycles. Only Kato et al. (1981) investigated the overtaking involving bicycles using experimental and numerical tests. However, this study only analysed the evolution of aerodynamic forces during a controlled manoeuvre, without testing the influence of speed or distance between the interacting bodies.

Lastly, cyclists risk perception of motor vehicles overtaking them on rural roads has not been researched. On the contrary, some studies focused on this variable on urban environments, measuring it using 5 or 10-point scales. Winters et al. (2012) found that perceived risk affected route choice, after interviewing a sample of cyclists on different routes. Parkin et al. (2007) 
compared perceived risk with bicycle infrastructure and its acceptability. They interview cyclists that observed video clips recorded from a moving bicycle. However, the variables that affect urban cycling could be very different from those related with sport and leisure cycling on two lane rural roads. On urban roads, the presence of signalized intersections, parked cars or separated tracks is crucial, but these factors are not present (or are less frequent) on two-lane rural roads.

Previous research on motor vehicle overtaking bicycles on rural roads has been centred on the study of lateral clearance (Chapman and Noyce, 2012; García et al., 2015; Walker, 2007; Walker et al., 2014), being speed of motor vehicles not measured or analysed. However, there are evidences of the relationship among these variables. On the one hand, speed is a significant factor of aerodynamic forces between overtaken an overtaking vehicles (Ata and Langlois, 2011; Noger et al., 2005), on the other hand, it might be associated with the higher severity of rural bicycle crashes (Boufous et al., 2012; Spanish Traffic Directorate, 2013). The contribution of this paper, in comparison with previous research, was the simultaneous characterization of lateral clearance, motor vehicle speed and rider's subjective risk perception of overtaking process.

\section{OBJECTIVES AND HYPOTHESES}

The aim of this paper was the analysis of compliance and adequacy of the $1.5 \mathrm{~m}$ lateral distance criterion with respect of objective and subjective risk measures. The study had the following objectives:

- Compare the effect of lateral clearance and overtaking vehicle speed (and their combination, in terms of aerodynamic forces) with a rider's subjective and relative risk perception on the different road segments.

- Analysis of the compliance and adequacy of lateral clearance based criteria.

- Analysis of the effect of bicycle type, road alignment and presence of opposing traffic.

The initial hypothesis of this research was that both lateral clearance and overtaking vehicle speed affect the subjective perception of each road segment. The higher the lateral clearance and the lower the speed, the safer the rider perception. This agrees with aerodynamic forces between overtaking and overtaken vehicles. Besides, a higher proportion of heavy vehicles may affect the perception of risk. Consequently, the distance-based criterion would not be associated with consistent perceived risk levels.

\section{METHODOLOGY}

The observation of overtaking manoeuvres was carried out using an instrumented bicycle. A professional cyclist rode the bicycle on seven rural road segments, resulting in the characterization of each motor vehicle overtaking manoeuvre (García et al., 2015).

\subsection{Instrumented bicycle}

This research started with the development of a new, versatile, instrumented bicycle (Figure 1). The bicycle was installed with three video cameras to record information on cyclist environment. A front-view camera facilitated the detection of opposing vehicles. A rear-view high definition camera observed the overtaking vehicle approach. The third camera recorded cyclist's left side to observe in detail the overtaking manoeuvre. A $10 \mathrm{~Hz}$ GPS tracker continuously registered the position of the instrumented bicycle along the road segment. Video and GPS data were stored in a Racelogic VBOX data logger. 


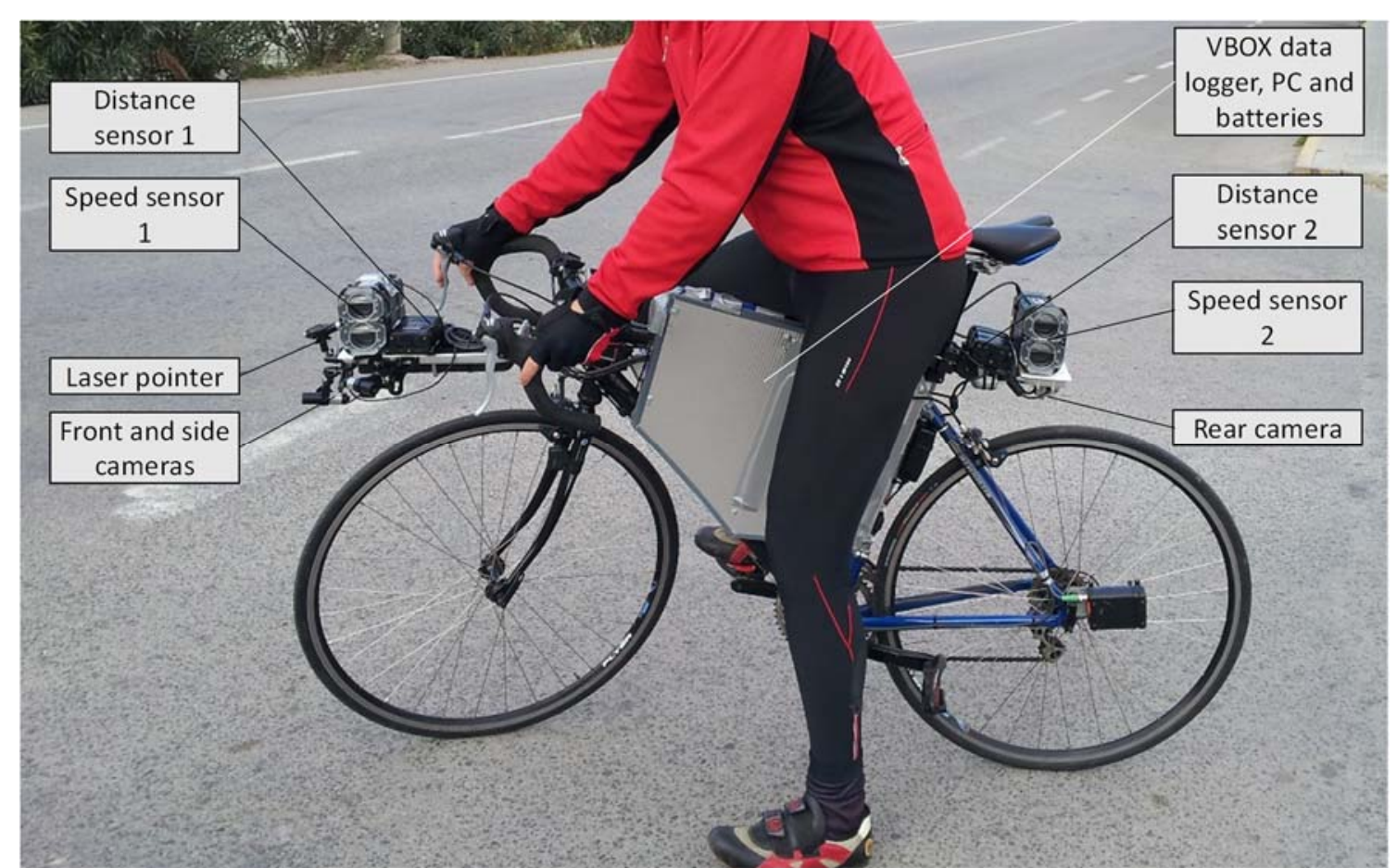

Figure 1. Instrumented bicycle

Besides, a Laser Technology Inc. T100 laser system measured the speed of overtaking vehicles. It consisted of a couple of laser rangefinders, perpendicular to bicycle axis, one of them in the front part of the bicycle and the other in the rear (Figure 2). The sensor provides the relative speed of the overtaking vehicle, after computing the time interval between the measurements of the two rangefinders. Additionally, two Laser Technology Inc. S200 rangefinders measured the lateral distance to the overtaking vehicle body. The measure was averaged between both sensors to get a more reliable value. A laptop connected to the laser sensors stored the data with a frequency of $12 \mathrm{~Hz}$. Two $12 \mathrm{~V}$ DC batteries provided power supply during the experiment.

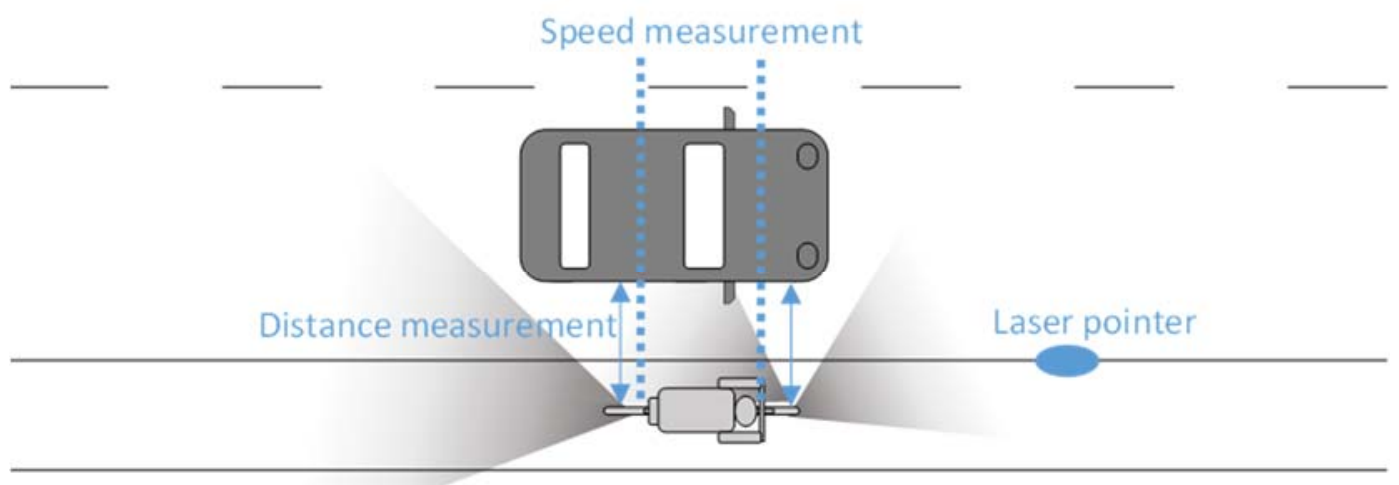

Figure 2. Field study layout

A laser pointer installed on the bicycle handlebar was oriented to the lateral marking in order to facilitate the rider to keep constant his lateral position.

Almost all the equipment was relatively small and was contained in a box attached to the bicycle frame. Laser sensors and small video cameras were installed in two small luggage racks. All the equipment was mounted in two different bicycles, a racing bicycle and a mountain-bike. 
The data collection was conducted on seven two-lane rural road segments, as seen in Table 1. Each segment was observed twice: the first day with an instrumented mountain-bike and the second with a racing instrumented bicycle, using the same equipment and configuration described above.

All data collection took place on weekdays, good weather conditions and dry pavement. During data collection, only one professional cyclist rode the instrumented bicycle. The bicycle speed was set within the range $15-25 \mathrm{~km} / \mathrm{h}$.

The lateral position adopted by the instrumented bicycle rider was the centre of the paved shoulder (or as close as to the outer edge if it did not exist).

\begin{tabular}{|c|c|c|c|c|c|c|c|}
\hline \multirow[b]{2}{*}{ Site } & \multirow[b]{2}{*}{ Road } & \multirow[b]{2}{*}{$\begin{array}{l}A A D T \\
\text { (veh) }\end{array}$} & \multirow{2}{*}{$\begin{array}{l}\text { Lane } \\
\text { width } \\
(\mathrm{m})\end{array}$} & \multirow{2}{*}{$\begin{array}{l}\text { Shoulder } \\
\text { width } \\
\text { (m) }\end{array}$} & \multirow[b]{2}{*}{$\begin{array}{l}\text { Length } \\
(\mathrm{km})\end{array}$} & \multicolumn{2}{|c|}{ Overtaking manoeuvres } \\
\hline & & & & & & $\begin{array}{l}\text { Mountain- } \\
\text { bike }\end{array}$ & $\begin{array}{l}\text { Racing } \\
\text { bicycle }\end{array}$ \\
\hline 1 & CV-3005 & 2,635 & 3.50 & 1.50 & 1.2 & 184 & 86 \\
\hline 2 & CV-315 & 7,935 & 3.15 & 2.50 & 5.0 & 182 & 189 \\
\hline 3 & CV-376 & 4,437 & 3.25 & 0.50 & 6.5 & 105 & 98 \\
\hline 4 & CV-310 & 6,416 & 3.15 & 1.50 & 5.3 & 232 & 261 \\
\hline 5 & CV-333 & 4,053 & 3.05 & 1.10 & 5.5 & 156 & 153 \\
\hline 6 & CV-405 & 14,800 & 3.50 & 1.00 & 7.3 & 529 & 529 \\
\hline 7 & $\mathrm{~N}-225$ & 5,412 & 3.50 & 1.50 & 7.0 & 172 & 74 \\
\hline
\end{tabular}

Table 1. Study road segments

The selection of the road segments covered a wide range of geometric characteristics, including various lane widths, shoulder widths, rolling and flat terrain. Besides, the segments covered various traffic volumes, being the average annual daily traffic (AADT) between 2,635 and 14,800 vehicles.

During the experiment, the bicycles rode roundtrips on the selected segments. The total distance travelled was $341 \mathrm{~km}$ for the mountain bike and $306 \mathrm{~km}$ for the racing bicycle, during 17:00 $\mathrm{h}$ and 14:30 $\mathrm{h}$, respectively. Up to 2,950 overtaking manoeuvres were observed, being around $50 \%$ observed from the mountain bike and $50 \%$ from the racing bicycle.

Based on the collected sample size, it was verified that maximum estimation error for the calculation of mean lateral clearance and mean speed (see definitions below) was in almost all cases under $5 \%$.

\subsection{Data reduction}

After data collection, the laser measurement device T100 provided the timestamp of each vehicle that overtook (or crossed) the instrumented bicycle during data collection. At every overtaking or crossing event, the distance measurement devices S200 obtained the distance between the bicycle axis and the motor vehicle body (named $d$ ). Additionally, the GPS data provided the geographic coordinates of every event and the bicycle speed $(V b)$. Geographic coordinates were converted to the road specific reference system (Station and direction). 
By filtering all the registered data considering the value of distance $d$, overtaking (a vehicle travelling in the same direction) or crossing events (a vehicle travelling in the opposing direction) were separated. This classification was verified by checking in the video recording every manoeuvre. At the same time, the observation of the video facilitated the characterization of the following variables:

- Overtaking vehicle category: sedan, van, truck, bus, etc. This classification was aggregated to four different types, according to vehicle size (because of the potential effect of aerodynamic forces). Motorcycles were not detected by laser sensor. Taken into account their lower volume as well as their lower frequency, they have not been considered in the study:

o Passenger car.

o Small van or SUV.

o Large van.

o Truck or bus.

- Overtaking vehicle crosses thee centreline (binary variable)

- Overtaking vehicle left lane occupation time (s), in case previous variable were positive.

After that, the following overtaking dynamic variables were characterized:

- Bicycle speed: $V b$.

- Relative speed: $d V$ (directly from laser speed measurement device).

- Motor vehicle speed: $V v=V b+d V$.

- Lateral spacing: directly from distance measurement device, $d$.

- Lateral clearance:

o $\quad c=d$ - half handlebar width - side mirror width, for light vehicles and small trucks.

o $c=d$-half handlebar width, for large trucks.

The Figure 3 shows the main distance and speed variables.

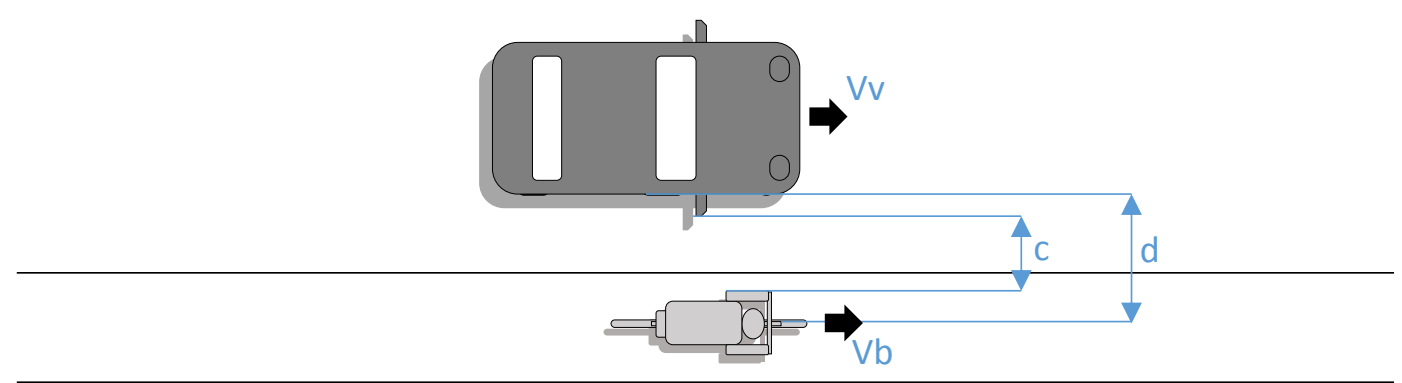

Figure 3. Lateral distance and speed-related variables

The definition of two different measures may account for the two different safety issues associated with motor vehicle overtaking, according to Ata and Langlois (2011). Firstly, lateral spacing represents the distance to the motor vehicle body and may correspond to the aerodynamic effect. Secondly, the lateral clearance is the physical space available between the motor vehicle and the bicycle, and may correspond to the collision risk.

Based on the relationship between lateral forces, lateral distance, speed of the overtaking vehicle, and size of the overtaking vehicle, six alternative variables were calculated for each single overtaking manoeuvre. The objective of calculating these variables was the study of the combined effect of clearance and speed. Because of the absence of information about $C_{y}$ and $\rho$ (from Equation 1) the proposed values do not represent forces, although they may be proportional to them. The following list shows the six alternative variables: 
- $\quad V v^{2} / d$.

- $\quad V v^{2} \cdot(3-d)$, based on Queensland (Australia) regulations (Quensland Government Department of Transport and Main Roads, 2004) as well as to Noger et al. (2005).

- $\quad V v^{2} / d \cdot$ Frontal area.

- $\quad V v^{2} / d \cdot$ Side area.

- $\quad V v^{2} \cdot(3-d) \cdot$ Frontal area.

- $\quad V v^{2} \cdot(3-d) \cdot$ Side area.

Where:

- $\quad V v$ is the speed of the vehicle in $\mathrm{m} / \mathrm{s}$.

- $d$ is the lateral spacing in $\mathrm{m}$.

- Areas are in $\mathrm{m}^{2}$. Different values of side area and frontal area were assigned to each vehicle category, according to their average sizes.

Besides, after data collection, the cyclist was interviewed in order to characterize his subjective perception of the road segment, compared to other data collection sites. This facilitated the evaluation of the perceived risk of each data collection site in relation to the other ones, which was reviewed after adding each new location. The following open-response questions were asked to the cyclist after each session:

- Describe subjective feeling about risk perception.

- Identify the most critical factors: narrow lanes, heavy vehicles, speed, etc.

- Rank this location from 1 to 5, comparing it to the previous ones.

According to this, a ranking of locations was established, from 1 (the one perceived as safest) to 5 (the one perceived as most dangerous) (Table 2). It should be taken into account that this ranking is a subjective and relative classification, as it depended only on one cyclists.

\begin{tabular}{|c|c|c|}
\hline Site & Road & Risk Ranking \\
\hline 1 & CV-3005 & 3 \\
\hline 2 & CV-315 & 3 \\
\hline 3 & CV-376 & 4 \\
\hline 4 & CV-310 & 3 \\
\hline 5 & CV-333 & 2 \\
\hline 6 & CV-405 & 5 \\
\hline 7 & N-225 & \multicolumn{2}{|c|}{} \\
\hline
\end{tabular}

Table 2. Subjective risk perception ranking

The presence of only one cyclist limited partially the validity of the risk evaluation, because there is not an absolute value of perceived risk. Relative differences between locations can still reasonably understood, though. On the contrary, the main advantage of having one cyclist was the possibility of using such highly instrumented bicycle on various road segments, obtaining a repeated measurement avoiding possible inter-individual differences between different cyclists.

\section{RESULTS}

The first objective of this paper was to compare the lateral distance (either spacing or clearance) and motor vehicle speed with the subjective risk perception. Analysing this relation, the results 
might indicate which variable (or which combination of variables) has the most significant impact on the perception of risk.

\subsection{Subjective risk perception, speed and clearance}

In order to achieve this result, the value of different dynamic variables for every risk perception levels was studied. Figure 4 shows the box-plot of the variables for each subjective risk level. The sample of every registered overtaking manoeuvre is plotted here. The factor plotted in the horizontal axis is the subjective risk perception (ranking from 1 to 5 ) and the dependent variable in the vertical axis is either the lateral clearance, spacing, or speed or a combination of variables, as specified in each sub-figure.

As can be seen in Figure 4, the relationship between risk perception and lateral distance (or lateral clearance) was unclear, as some locations which presented higher distances and clearances were associated with higher perceived risk levels. Specifically, the locations with lower risk perception (level 1) had a statistically significantly shorter spacing (or clearance), but locations with higher risk perception (level 5) presented a statistically significant higher spacing (or clearance) compared to the previous risk level (level 4). Moreover, the influence of speed at levels 1 to 4 was not logical, because locations with risk level 4 had significantly lower speed (or relative speed) than locations with level 3 . The risk level 5 did correspond with higher speeds, though.
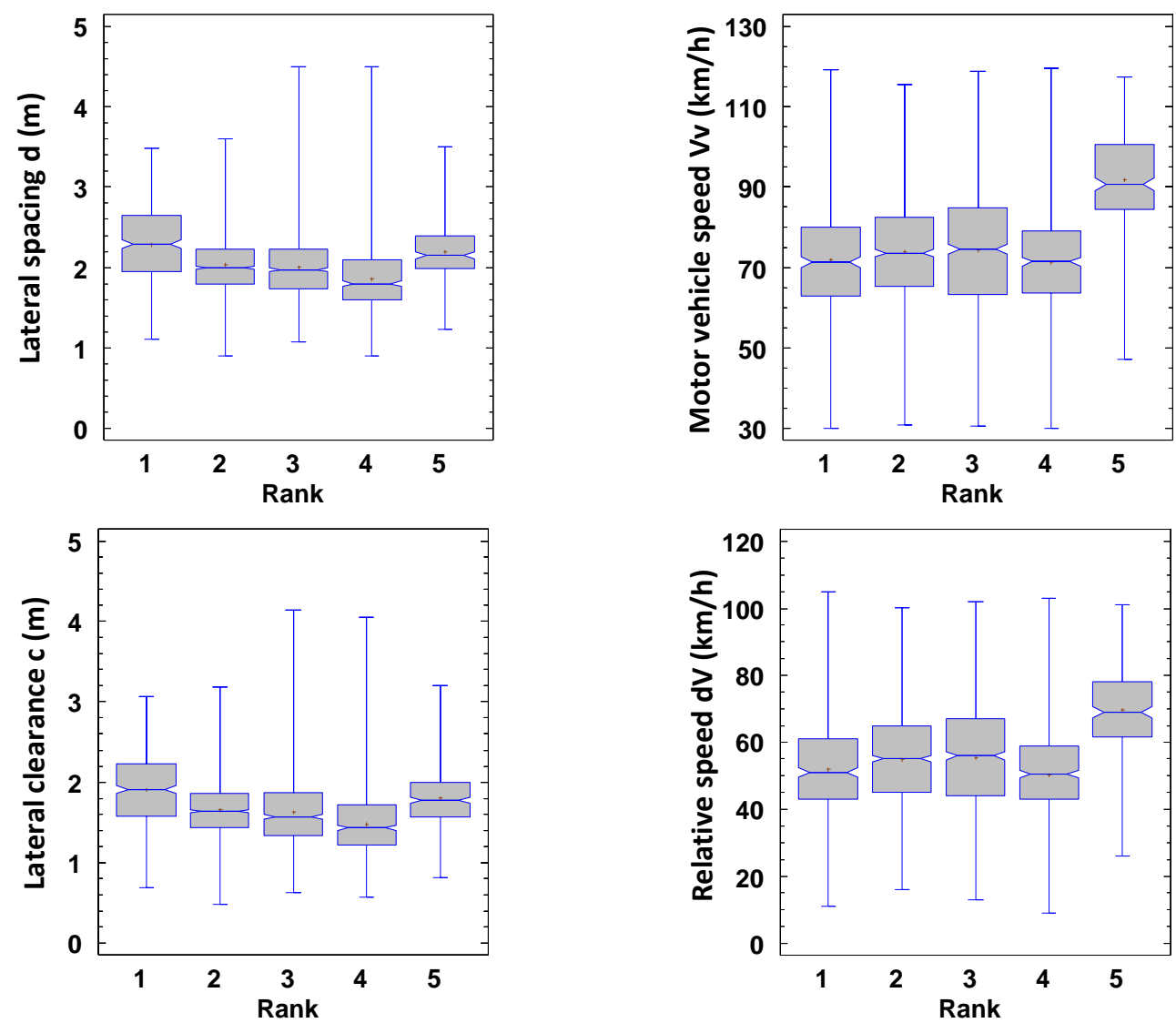

distance-based variables

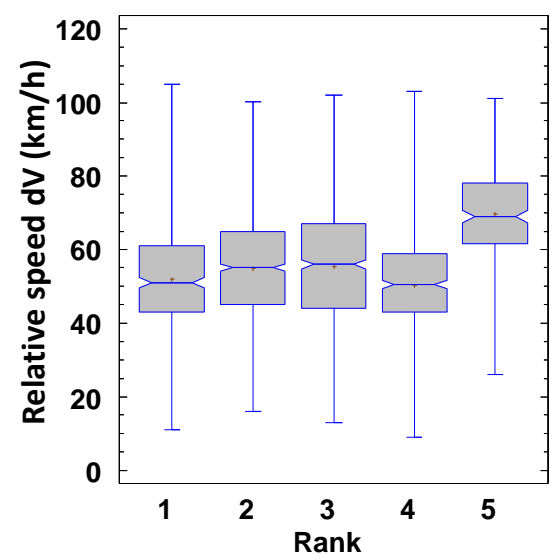

speed-based variables

Figure 4. Analysis of the differences on lateral distance and speed among subjective risk perception levels 
Additionally, the Figure 5 shows the percent of heavy vehicles (trucks or buses) that overtook the bicycle on each road segment. As can be seen, the most dangerous perceived risk level also corresponded to a significantly higher percent of heavy vehicles.

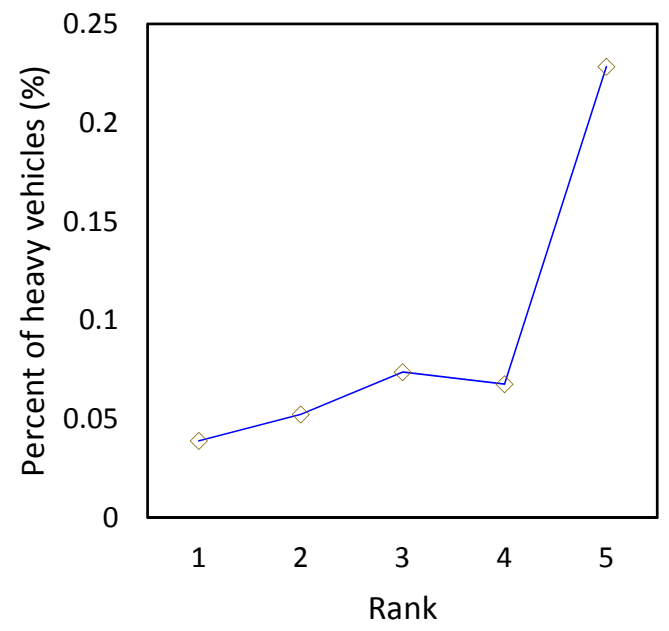

Figure 5. Analysis of the percent of heavy vehicles among different risk perception levels

From the previous analysis, the subjective risk perception might be related to lateral distance, speed and proportion of heavy vehicles. However, the individual effect of each variable was not evident. For this reason, the following analysis focused on the definition of alternative variable that combine the effect of distance, speed and size of the vehicle. According to the initial hypothesis, the aerodynamic forces between overtaking and overtaken vehicles may explain the subjective risk perception.

The relationship between the dynamic (or aerodynamic variable) and the subjective risk perception of the previous variables is presented in Figure 6. LSD-intervals are plotted for each variable to show the tendencies. However, as the proposed variables did not come, in general, from normal distributions, the non-parametric Kruskall-Wallis test was used to compare the medians instead of the means.

As can be seen, the consideration of the different combinations of variables showed a more strong relationship between subjective risk perception and average dynamic characteristics of the overtaking manoeuvres. With considering the relationship of $V^{2} / d$, there are still some cases where level 4 would have less dynamic (or aerodynamic) effect than level 3 . However, using the relationship $V^{2} \cdot(3-d)$, as recommended by Ata and Langlois (Ata and Langlois, 2011) and Noger et al. (Noger et al., 2005), the aerodynamic effect increases with risk ranking.

The Kruskall-Wallis test checked the null hypothesis that the medians within each of the five levels were the same. The results showed that there were statistically different medians at the 95\% confidence levels. In all cases, there were differences between level 1 and the rest, and between level 5 and the rest. Only with the relationship $V^{2} \cdot(3-d)$ additional differences between levels 2 and 4 were also found. 


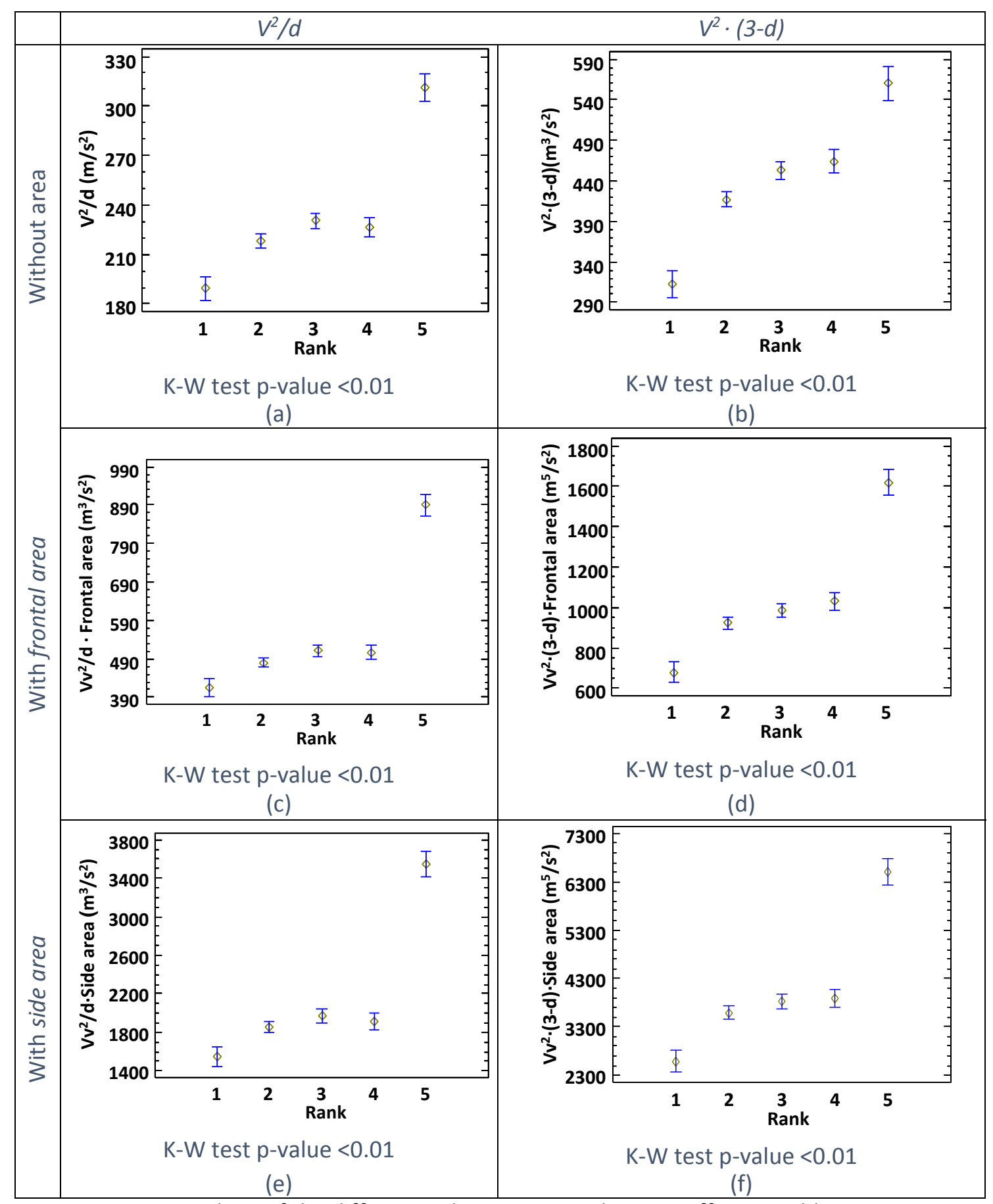

Figure 6 . Analysis of the differences between aerodynamic effect variables among the different risk perception levels

\subsection{Overtaking standards}

The second objective of the paper was to analyse the compliance of the lateral distance based criterion, as well as the assessment of their adequacy, based also on subjective risk perception.

As stated in the introduction, the current standard in Spain, as well as in many other countries had a $9 \%$ of noncompliance in terms of lateral spacing, increasing to a $36 \%$ of noncompliance in 
Besides, based on the results of Figure 6, the Figure 7 shows the values of the variable $V v^{2} \cdot(3-$ d) for different combinations of speed and lateral distance. This would result in an increasing risk with speed. These values are compared with the $1.5 \mathrm{~m}$ lateral separation standard, showing that it did not provided enough safety at locations with higher mean overtaking speeds.

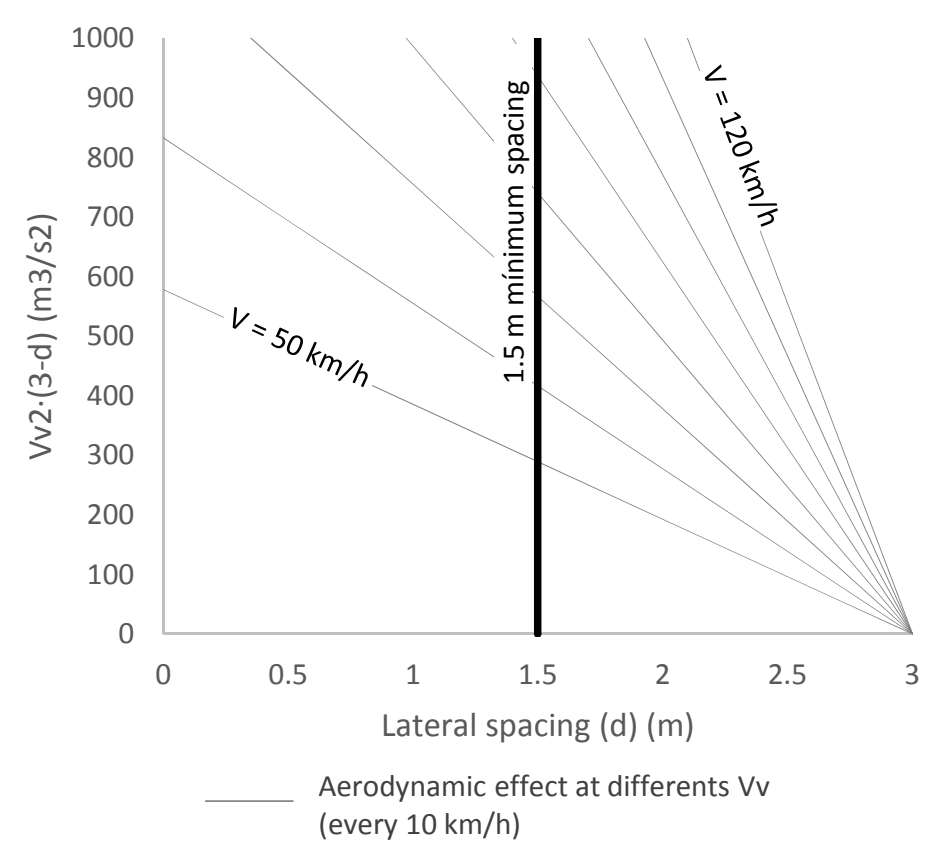

Figure 7. Lateral distance-based standard

Besides, Figure 8 shows the average value of $v v^{2} \cdot(3-d)$ for locations with subjective risk perception equal to 1, 3 and 5 (as an example). By establishing a target perceived risk level, a different lateral separation is required at each speed level. According to the Figure 9, the safest perceived level is achieved at $1.5 \mathrm{~m}$ at $50 \mathrm{~km} / \mathrm{h}$, but it is needed up to $2.75 \mathrm{~m}$ at $120 \mathrm{~km} / \mathrm{h}$. If the regulation were set as a variable lateral separation (i.e. to ensure a target perceived risk of 1 , the safest, at all locations), depending on the speed, the percentage of non-compliance would have been $44 \%$ on the observed sample. 


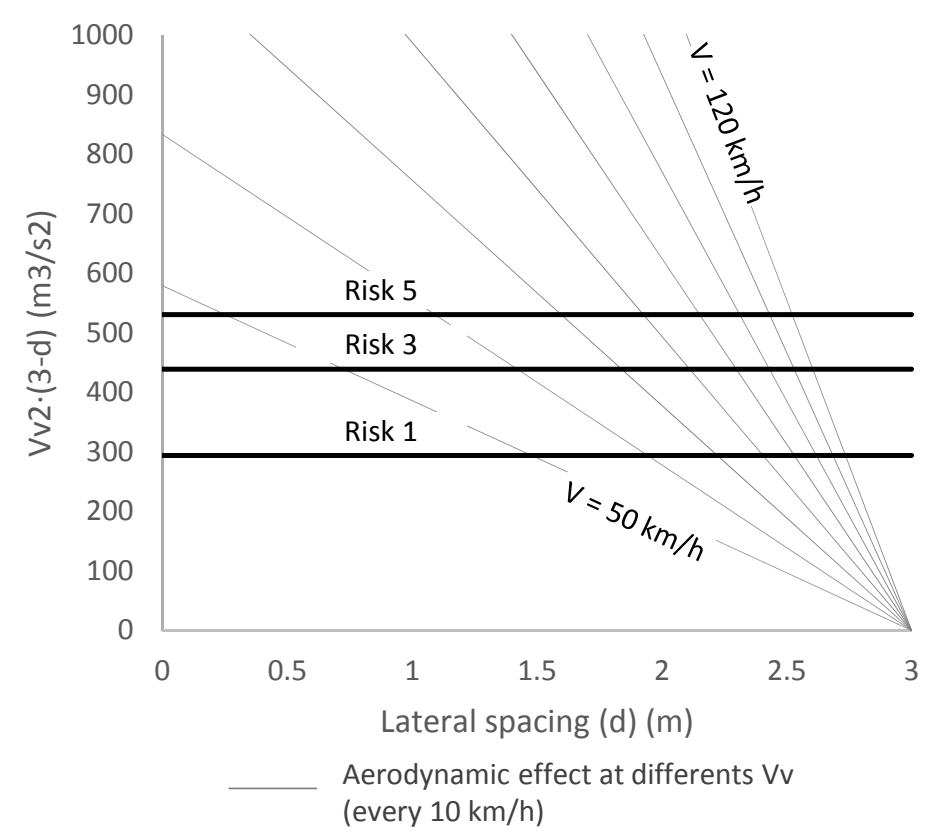

Figure 8. Perceived risk-based standard

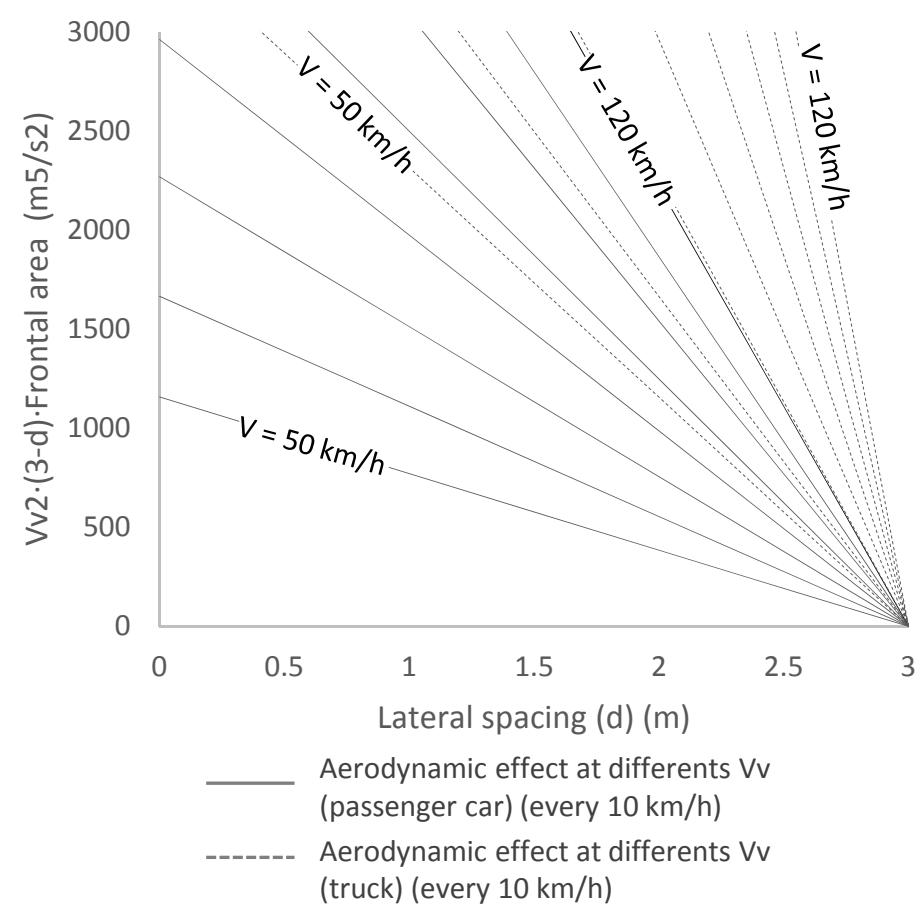

Besides, as seen in Figure 9, if the presence of heavy vehicle is significant, it should be noted that the aerodynamic effect would be much higher, and the minimum lateral separation should be increased to obtain the same perceived risk level. Bicycle type, road and traffic 
The effect of additional factors on the selected variable $V v^{2} \cdot(3-d)$ was also analysed. Figure 10 shows the influence of bicycle type, road alignment and presence of opposing vehicles on the value of $v v^{2} \cdot(3-d)$. The Kruskall-Wallis test compared the medians for each level factor. The results showed a reduced but significant effect of bicycle type (being the median of $\mathrm{V}^{2} \cdot(3-\mathrm{d})$ slightly lower if the overtaken bicycle was a mountain-bike). This might be associated with the lower lateral spacing $d$ if a racing bicycle was overtaken (the mean of $d$ was $15 \mathrm{~cm}$ lower on racing bicycle, being $1.96 \mathrm{~m}$ and $2.11 \mathrm{~m}$ respectively).

In relation to road alignment, the median of $V^{2} \cdot(3-d)$ was significantly higher for tangent sections, compared to curves. Both lateral spacing and speed were higher on tangent sections.

The effect of the presence of opposing vehicles on $V^{2} \cdot(3-d)$ was not significant. The lateral spacing $d$ was lower in presence of opposing vehicles (the mean of $d$ was $9 \mathrm{~cm}$ lower, being 1.98 $\mathrm{m}$ and $2.07 \mathrm{~m}$ respectively). However, the speed of motor vehicles was reduced in presence of opposing vehicles (the mean of $v v$ was $3.5 \mathrm{~km} / \mathrm{h}$ lower, being $74.1 \mathrm{~km} / \mathrm{h}$ and $77.6 \mathrm{~km} / \mathrm{h}$ in presence and in absence of opposing vehicles, respectively).

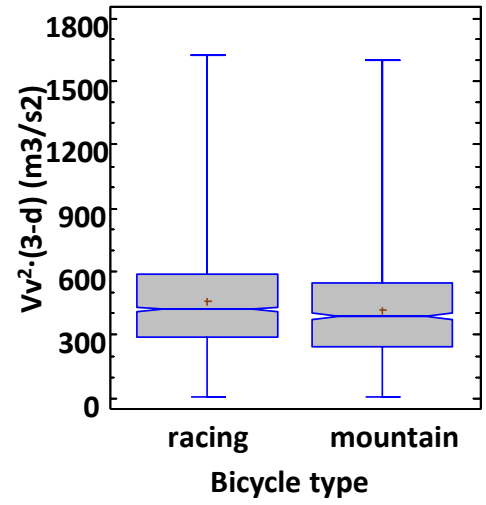

Bicycle type
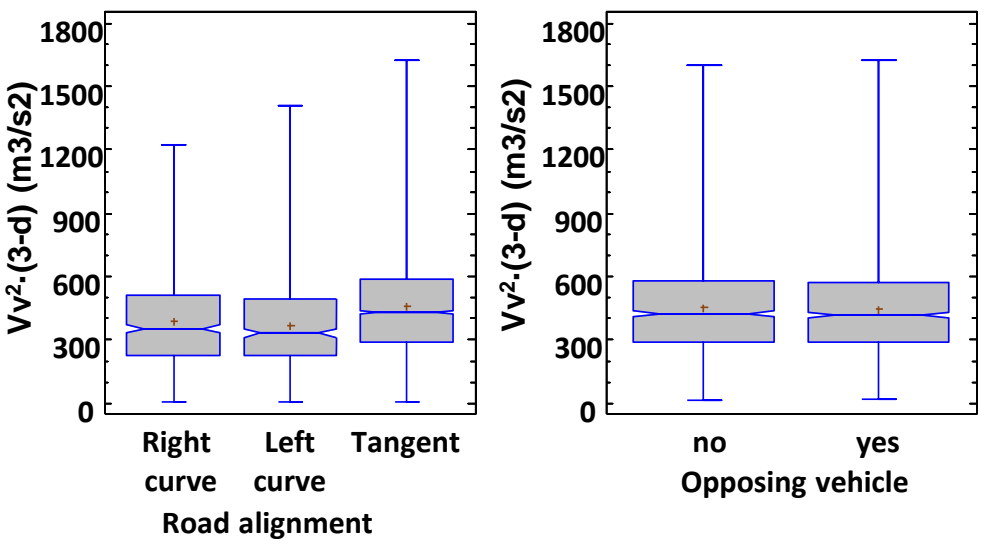

Figure 10. Effect of bicycle type, road alignment and opposing vehicle

\section{DISCUSSION}

The results of this paper have been compared to previous work. However, the number of variables considered in this study is much higher, including the speed of overtaking vehicles as well as the subjective risk perception differences among highways. Taking into account the potential importance of the speed of motor vehicles in overtaking manoeuvres, the developed data collection system improved significantly on previous research carried out on two-lane highways (Chapman and Noyce, 2012; Walker, 2007).

According to Walker (2007), heavy vehicles (trucks or buses) kept a lower clearance, being the overtaking unsafe. This is in agreement with present results. Besides, the present research also showed that the effect of bicycle type was also significant. Chapman and Noyce (2012) observed an average overtaking lateral spacing of 6.3 feet $(1.92 \mathrm{~m})$, concluding that most of vehicles overtook keeping a distance over the minimum 3 feet requirement. They stated that, contrary to cyclists' opinion, most of drivers kept sufficient lateral distance, being the manoeuvres safe. However, those authors did not analyse the speed of motor vehicles, which had a significant impact on risk perception, as this research has found.

Most countries regulate the overtaking of bicycles on two-lane rural road by establishing a minimum lateral separation between the motor vehicle and the bicycle. Generally, this lateral 
separation does not depend on speed or on vehicle type, although the effect of heavy vehicle has been reported (Chapman and Noyce, 2012). In Spain, as well as in many other countries the minimum distance is $1.5 \mathrm{~m}$ (Ministerio del Interior, 2003). In some US states, this is equal to $3 \mathrm{ft}$ (around $1 \mathrm{~m}$ ). Only the Queensland Department of Transport (Quensland Government Department of Transport and Main Roads, 2013) does recommend $1 \mathrm{~m}$ if motor vehicle travels under $60 \mathrm{~km} / \mathrm{h}$ and 1.5 over $60 \mathrm{~km} / \mathrm{h}$.

The compliance of the Spanish $1.5 \mathrm{~m}$ regulation (Ministerio del Interior, 2003) was analysed from collected data. However, the differences between lateral spacing and lateral clearance are not taken into account in the standard. This resulted in a $9 \%$ of noncompliance if lateral spacing was considered. However, this value increased to $36 \%$ of noncompliance if lateral clearance was taken into account.

However, most of these standards are not the result of any scientific research. They do not mention generally any scientific evidence to justify the proposed distance. The results of this research have demonstrated that the lateral distance is not the only factor that affected risk perception. In fact, the rider's risk perception was affected by a combination of parameters, being the most significant the lateral distance and the speed, as well as the proportion of heavy vehicles. Those factors are components of the aerodynamic effect of a motor vehicle passing by a bicycle. In absence of a deeper psychological study on how cyclists perceive risks associated with the overtaking manoeuvre (which would require the inclusion of a larger sample of individuals, taking into account their social, geographical, or cultural variety), the results clarify that there are more factors affecting the perceived risk rather than only the lateral distance.

The objective risk at the observed sites could not be measured, though. As only one cyclist was interviewed, no information on the absolute risk could be extracted. Based on an experiment with a larger samples of cyclists Winters et al. (2012) demonstrated that risk and risk perception were related (although with certain inconsistencies). This was not possible in this research, which only assumed a relative classification between locations.

\section{CONCLUSIONS AND RECOMMENDATIONS}

This research developed a methodology to study how motor vehicles overtake bicycles on twolane rural roads. This method was based on an instrumented bicycle riding along different rural road segments, in order to observe every overtaking motor vehicle. The major contribution to previous research in this field was the addition of new variables to the overtaking manoeuvre characterization, including overtaking vehicle speed based and rider's risk perception.

According to the first study objective, the results characterized the link between lateral separation and speed and rider's risk perception. The main conclusions were as follows:

1. A higher lateral separation is not always related, in this experiment, with lower perceived risk levels.

2. Higher speeds and the presence of heavy vehicles are always present in the highest perceived risk levels.

3. The combination of lateral separation and speed, which is proportional to aerodynamic forces between overtaking and overtaken vehicles, showed the better correlation with the average risk perception.

The second objective was to assess the current lateral distance standards, showing that they are not sufficient to warrant safe overtaking manoeuvres, as they do not take into account the speed or the presence of heavy vehicles. In fact, different values of lateral spacing $(1.5 \mathrm{~m}$ at $50 \mathrm{~km} / \mathrm{h}$ and $2.75 \mathrm{~m}$ at $120 \mathrm{~km} / \mathrm{h}$ ) were associated with the same, lowest risk perception levels. 
From the results of this part of the paper, and taking into account that the lateral clearance increased with lane and shoulder width (García et al., 2015), the provision of adequate shoulders could be an appropriate mechanism to ensure safe overtaking manoeuvres. Additionally, the proposed criteria should define accurately whether the minimum distance corresponds to spacing or clearance, in base on the differences observed in this research.

With respect of the last objective, the analysis of other road, bicycle and traffic factors, the following conclusions were obtained:

1. The combined variable of lateral separation and speed was higher on tangent sections, compared to right or left curves.

2. Motor vehicle drivers reduced slightly the speed in presence of opposing traffic, when overtaking a bicycle. This may have an effect on the operation of two-lane rural roads.

This work adopted average risk perception levels for each location based on a unique cyclist. This allowed the identification of relative differences between different road and traffic conditions. However, if the intention were to establish criteria based on absolute risk values, a larger sample of cyclists would be required. Moreover, the influence of the distance, speed and presence of heavy vehicles should be verified with the analysis of crash data, if it is available.

Despite the above mentioned limitations, this research provided an additional scientific support to improve geometric design of rural two-lane highways. This study demonstrated that risk perception is not only affected by lateral separation, but also by speed and presence of heavy vehicles. Those factors should be taken into account to provide safer conditions for cyclists.

\section{AKNOWLEDGEMENTS}

Authors would like to thank Spanish Ministry of Economy for subsidizing partially this research, as part of the research project with reference code TRA2013-42578-P.

\section{REFERENCES}

Ata, M.K., Langlois, R.G., 2011. Factoring Cycling in Transportation Infrastructure : Design Considerations Based on risk Exposure. ITE Journal August 201, 49-53.

Boufous, S., de Rome, L., Senserrick, T., Ivers, R., 2012. Risk factors for severe injury in cyclists involved in traffic crashes in Victoria, Australia. Accident; analysis and prevention 49, 404-9. doi:10.1016/j.aap.2012.03.011

Chapman, J.R., Noyce, D.A., 2012. Observations of Driver Behavior During Overtaking of Bicycles on Rural Roads. Transportation Research Record: Journal of the Transportation Research Board 2321, 38-45. doi:10.3141/2321-06

Corin, R.J., He, L., Dominy, R.G., 2008. A CFD investigation into the transient aerodynamic forces on overtaking road vehicle models. Journal of Wind Engineering and Industrial Aerodynamics 96, 1390-1411. doi:10.1016/j.jweia.2008.03.006

García, A., Angel-Domenech, A., Llorca, C., Agustín-Gómez, F., Ferrer, V., 2015. Effects Of Road Geometry On The Interaction Between Bicyclists And Motor Vehicles On Two-Way Rural Highways, in: 5th International Symposium on Highway Geometric Design. Vancouver (Canada). 
Hamann, C., Peek-Asa, C., 2013. On-road bicycle facilities and bicycle crashes in lowa, 20072010. Accident; analysis and prevention 56, 103-9. doi:10.1016/j.aap.2012.12.031

Kato, Y., Iwasa, T., Matsuda, M., Miyai, Y., 1981. Aerodynamic Effects to a Bicycle Caused by a Passing Vehicle. SAE Technical Papers. doi:10.4271/811425

Kay, J.J., Savolainen, P.T., Gates, T.J., Datta, T.K., 2014. Driver behavior during bicycle passing maneuvers in response to a Share the Road sign treatment. Accident; analysis and prevention 70C, 92-99. doi:10.1016/j.aap.2014.03.009

Klassen, J., El-Basyouny, K., Islam, M.T., 2014. Analyzing the severity of bicycle-motor vehicle collision using spatial mixed logit models: A City of Edmonton case study. Safety Science 62, 295-304. doi:10.1016/j.ssci.2013.09.007

Love, D.C., Breaud, A., Burns, S., Margulies, J., Romano, M., Lawrence, R., 2012. Is the threefoot bicycle passing law working in Baltimore, Maryland? Accident; analysis and prevention 48, 451-6. doi:10.1016/j.aap.2012.03.002

Ministerio del Interior, 2003. Real Decreto 1428/2003, de 21 de noviembre, por el que se aprueba el Reglamento General de Circulación.

Noger, C., Regardin, C., Széchényi, E., 2005. Investigation of the transient aerodynamic phenomena associated with passing manoeuvres. Journal of Fluids and Structures 21, 231-241. doi:10.1016/j.jfluidstructs.2005.05.013

Osberg, J.S., Stiles, S.C., Asare, O.K., 1998. Bicycle safety behavior in Paris and Boston. Accident Analysis \& Prevention 30, 679-687. doi:10.1016/S0001-4575(97)00097-3

Parkin, J., Wardman, M., Page, M., 2007. Models of perceived cycling risk and route acceptability. Accident; analysis and prevention 39, 364-71. doi:10.1016/j.aap.2006.08.007

Quensland Government Department of Transport and Main Roads, 2004. Cross Section, in: Road Planning and Design Manual.

Quensland Government Department of Transport and Main Roads, 2013. Queensland Road Rules for Cyclists.

Savolainen, P.T., Gates, T.J., Todd, R.G., Datta, T.K., Morena, J.G., 2012. Lateral Placement of Motor Vehicles When Passing Bicyclists. Transportation Research Record: Journal of the Transportation Research Board 2314, 14-21. doi:10.3141/2314-03

Spanish Traffic Directorate, 2013. Main Figures on Road Safety Data Spain 2013.

Tin Tin, S., Woodward, A., Ameratunga, S., 2013. Incidence, risk, and protective factors of bicycle crashes: findings from a prospective cohort study in New Zealand. Preventive medicine 57, 152-61. doi:10.1016/j.ypmed.2013.05.001 
Uystepruyst, D., Krajnović, S., 2013. Numerical simulation of the transient aerodynamic phenomena induced by passing manoeuvres. Journal of Wind Engineering and Industrial Aerodynamics 114, 62-71. doi:10.1016/j.jweia.2012.12.018

Walker, I., 2007. Drivers overtaking bicyclists: objective data on the effects of riding position, helmet use, vehicle type and apparent gender. Accident; Analysis and Prevention 39, 417-25. doi:10.1016/j.aap.2006.08.010

Walker, I., Garrard, I., Jowitt, F., 2014. The influence of a bicycle commuter's appearance on drivers' overtaking proximities: an on-road test of bicyclist stereotypes, high-visibility clothing and safety aids in the United Kingdom. Accident; analysis and prevention 64, 6977. doi:10.1016/j.aap.2013.11.007

Winters, M., Babul, S., Becker, H.J.E.H.J., Brubacher, J.R., Chipman, M., Cripton, P., Cusimano, M.D., Friedman, S.M., Harris, M.A., Hunte, G., Monro, M., Reynolds, C.C.O., Shen, H., Teschke, K., 2012. Safe cycling: how do risk perceptions compare with observed risk? Canadian journal of public health = Revue canadienne de santé publique 103, eS42-7. 